\title{
MODEL FOR PREDICTING MIX FORMULATION IN THE PRODUCTION OF INSULATING REFRACTORY BRICKS USING NIGERIAN FIRE-CLAYS AND COCONUT SHELL
}

\author{
E. O. Obidiegwu ${ }^{1, *}$, E. F. Ochulor ${ }^{2}$ and H. E. Mgbemere ${ }^{3}$ \\ 1, 2, 3, Dept. Of Metallurgical and Materials Engr'G, Univ. Of Lagos, AKoka, Lagos State, NiGeria \\ E-mail addresses: ${ }^{1}$ eobidiegwu@unilag.edu.ng; ${ }^{2}$ eochulor@unilag.edu.ng, \\ 3 hmgbemere@unilag.edu.ng
}

\begin{abstract}
Lack of appropriate mix formulation has the tendency to degrade the strength of refractory bricks. This paper presents a model developed for evaluation and prediction of mix formulation for production of insulating refractory using Osiele and Ukpor fireclays blended with coconut shell particulates. The chemical compositions of the raw materials were analysed. The samples were prepared by mixing the clays and coconut shell of grain sizes $212-600 \mu m$. Then air and oven dried for 24 hours at room temperature and at $110^{\circ} \mathrm{C}$ respectively. Thereafter, sintered at temperatures between 950 to $1200^{\circ} \mathrm{C}$ at $50^{\circ} \mathrm{C}$ interval. The samples were tested for various properties. From the results, an Empirical Model relating the Composition and Property of the bricks was developed. $\varphi_{k l m}=\alpha_{i j} C^{4}+\beta_{i j} C^{3}+\gamma_{i j} C^{2}+\lambda_{i j} C+\eta_{i j}$. The results of the model show the trend similar to experimental. Deviational analysis conducted indicates that the deviation of model-predicted data from the experimental is between 2.25 - 8.9\%hence, 91- 97\% accuracy.
\end{abstract}

Keywords: Refractory, Coconut shell, empirical model, porosity and thermal conductivity.

\section{INTRODUCTION}

Insulating refractories bricks are thermal barriers that help to retain heat in furnaces and ovens in order to save energy. These are used in lining the walls of melting, heat treatment as well as heat regeneration furnaces and ovens where demand for maximum heat conservation is needed. This helps to minimize fuel consumption and maximize productivity. These bricks possess low strength, they are lightweight and have low thermal conductivity compared to dense bricks [1].

The insulating property of these refractory bricks depends on the degree of porosity. The later translates to increase in air pockets and low thermal conductivity. However, high degree of porosity induced by pore formers degrades the mechanical strength of the bricks as compared to a dense refractory brick [2].This can be attributed to lack of appropriate mix formulation.

The developed model is to predict accurately the quantity of pore former that can be blended with selected fireclays in order to produce insulating refractory bricks with appreciable strength.

Investigations and findings on producing insulating refractory bricks include a study on the development of insulating refractory ramming mass from some Nigerian refractory raw materials, conducted by [3]. From their results, two optimal ratios of ramming mass are recommended for use in lining melting furnaces such as rotary and crucible furnaces.

Studies on the effect of coal ash on some refractory properties of Kankara kaolin is also carried out; it was found that the linear shrinkage and apparent porosity of the bricks produced from Kankara clay blended with coal ash decrease with increasing percentage of coal ash addition [4].

The results from the study carried out on insulating refractory from organic wastes reveal that the thermal conductivity of refractory clays depend on the chemical properties, mineralogical composition, silica

* Corresponding author, tel: +234 - 803 - 581 - 2874 
content of the refractory and on the application temperature; [5]. The study suggests that low thermal conductivity is desirable for conservation of heat, as the porous refractory acts as an insulator. Light weight refractory bricks were manufactured using clay, rice husk and saw dust as the raw materials [6]. Various process parameters were investigated and the bricks with optimized properties were produced which can be used up to $1200^{\circ} \mathrm{C}$.

The effect of coal and wheat husk additives on the physical, thermal and mechanical properties of clay bricks was studied by [7]. In this study, various proportions of coal and wheat husk were used as additives in the initial ingredients of clay bricks. Microstructure, thermal conductivity, coefficient of thermal diffusivity, water absorption, shrinkage, compressive strength and bulk density of fired clay bricks with and without additives were investigated. Clay bricks containing 5-15 wt. \% additives were found to be within the permissible limits for most of the recommended standard specifications.

Successful researches have been made on how to produce insulating refractory bricks but none has been made on using coconut shell as pore former and how to develop a model to predict the mix formulation required to produce insulating refractory bricks with the required refractory properties. Therefore, this paper presents a model developed for quantitative evaluation and prediction of mix formulation for production of insulating refractory bricks from selected Nigerian fireclays blended with coconut shell particulates.

\section{MATERIALS AND METHODS}

The raw materials used for this research are Ukpor and Osiele clays collected from Nnewi South L.G.A of Anambra State and Abeokuta in Ogun State of Nigeria respectively. The samples collected for this study were at a depth of 3 meters down the threshold and 6 meters interval using digger and shovel. While the coconut shell (C.S) was collected from coconut chips producers at Ibadan, Nigeria. The chemical analysis of the as-received materials was conducted using Atomic Absorption Spectrometer (AAS) Perklin Elmer Analyst 200 model.

The as-received clays and coconut shell were air dried, crushed with a jaw crusher and ground to finer particles using ball milling machine at the Federal Institute of Industrial Research, Oshodi (FIIRO). The clay particulates were classified using sieve aperture of $212 \mu \mathrm{m}$, while the agroforestry wastes were classified using sieves of $212 \mu \mathrm{m}, 300 \mu \mathrm{m}, 425 \mu \mathrm{m}$, $500 \mu \mathrm{m}$ and $600 \mu \mathrm{m}$ apertures. The sieves were selected after a pre-test. The raw materials were weighed using a digital weighing machine (METTLER PJ 300). The mix formulation (body mix) of the materials were determined through pre-tests.

The weighed raw materials were compacted using semi-dry mix method with $40 \mathrm{ml}-60 \mathrm{ml}$ of water. The compaction was conducted in cleaned and oil lubricated moulds of different shapes and sizes (76.2 $x 76.2 \times 76.2 \mathrm{~mm}^{3}, 60 \times 60 \times 15 \mathrm{~mm}^{3}, 50 \times 75 \mathrm{~mm}^{2}, 95$ $\times 45 \times 12 \mathrm{~mm}^{2}$ and $220 \times 110 \times 65 \mathrm{~mm}^{3}$ for CCS, porosity, thermal shock resistance, linear shrinkage tests and for standard bricks respectively).

The refractory bricks produced were air-dried at atmospheric temperature for 24 hours and then oven dried for at least 24 hours in an electric oven at a temperature of $110^{\circ} \mathrm{C}$. This is to allow for the removal of moisture which might cause cracking during firing. Firing of bricks was conducted in an electric muffle furnace, at $950^{\circ} \mathrm{C}, 1000^{\circ} \mathrm{C}, 1050^{\circ} \mathrm{C}, 1100^{\circ} \mathrm{C}, 1150^{\circ} \mathrm{C}$, and $1200^{\circ} \mathrm{C}$ at the rate of $2.5^{\circ} \mathrm{C} / \mathrm{min}$. The Physical property (apparent porosity), the mechanical property (cold crushing strength) and thermal property (thermal conductivity) of the insulating refractory bricks were determined in accordance with [8] and [9].

The data obtained from the experiment conducted was used to develop the model that relates the refractory properties and mix formulation using Chapra's method of least square with the aid of Matlab software. This was done by obtaining the approximate equation by curve fitting the experimental graph using MATLAB. The MATLAB software generated the equation that best describe the curve.

\section{RESULTS AND DISCUSSION}

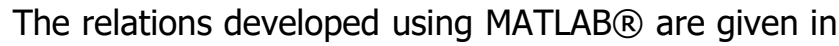
the equations below. The results of the model for thermal conductivity of refractory bricks produced from Osiele and Ukpor clay are shown in Equation 1 and 2 respectively. Where $\mathrm{K}$ stands for thermal conductivity and $\mathrm{x}$ stands for weight percentage composition of coconut shell.

$$
\begin{gathered}
K_{1}=-7 \times 10^{-9} x^{3}-2 \times 10^{-5} x^{2}-0.0012 x \\
+0.1004 \\
K_{2}=-6 \times 10^{-7} x^{3}+2 \times 10^{-5} x^{2}-0.0017 x \\
+0.0939
\end{gathered}
$$

The results of model for Porosity are shown in Equations 3 and 4 for Osiele and Ukpor clay respectively. $P_{1}$ and $P_{2}$ stands for Porosity of refractory 
bricks produced from Osiele and Ukpor clay respectively.

$$
\begin{aligned}
P_{1}=-0.0014 x^{3} & +0.0616 x^{2}+1.3984 x \\
& +19.166 \\
P_{2}=-0.0017 x^{3} & +0.0909 x^{2}+0.4347 x \\
& +31.850
\end{aligned}
$$

The results of Cold Crushing Strength are given in Equations 5 and $6 . \mathrm{CCS}_{1}$ and $\mathrm{CCS}_{2}$ stands for Cold crushing Strength of refractory produced from Osiele and Ukpor clay respectively

$$
\begin{aligned}
C C S_{1}= & 0.0195 x^{4}-1.942 x^{3}+67.055 x^{2}-1016.5 x \\
& +9923.9 \\
C C S_{2} & =0.0113 x^{4}-1.2916 x^{3}+51.530 x^{2}-908.62 x \\
& +8704.9
\end{aligned}
$$

The empirical models developed has accuracy of (91$98 \%$, this show strong correlation with the experimental findings.

\subsection{Thermal Properties}

\subsubsection{Thermal Conductivity of Bricks}

The results of thermal conductivity tests presented in Figures 1 and 2 show that the thermal conductivity decreases with increase in the percentage composition of the agro-wastes. This is in agreement with the results obtained by [4]. This trend can be attributed to an increase in the formation of pores that hinder heat transfer from one particle to another, since heat transfer in solids is mainly by conduction. When there is increase in porosity, entrapped air between the particles inhibits the rate of heat transfer [10]. These empty spaces or voids (though may contain air) insulate the thermal flow hence, the reduction in thermal conductivity of the samples as the percentage of C. S. (waste) admixture increases.

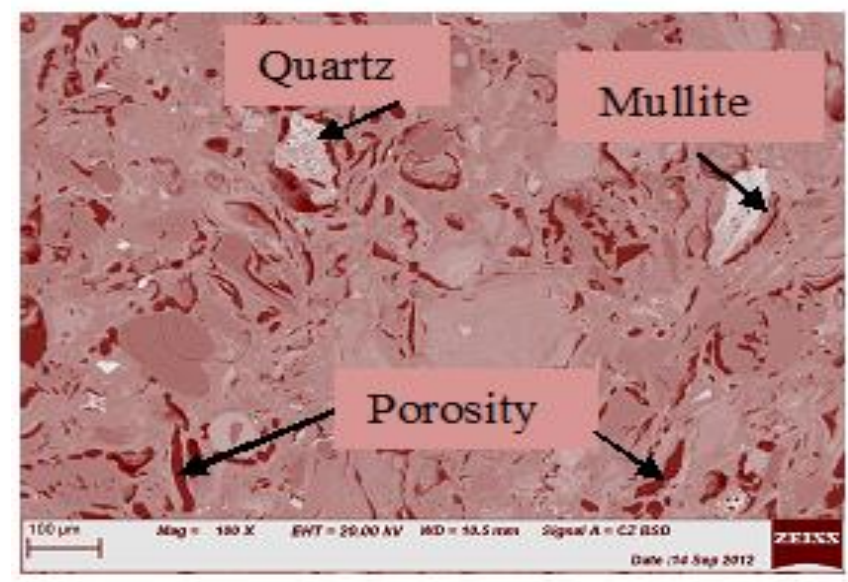

Plate $1: 0 \%$ additive fired at at $1150^{\circ} \mathrm{C}$, Scale: $100 \mu \mathrm{m}$
Plates 1 and 2 are the SEM micrograph showing the increase in porosity as a result of addition of coconut shell. Resulting to variation of thermal conductivity with coconut shell content.

\subsubsection{Model Validation}

In order to validate the accuracy of the models, the percentage deviation $\left(\delta_{i}\right.$ ) and average percentage deviation $(\bar{\delta})$ are used and it is given in Equation 4

$$
\delta_{i}=\frac{\left|K_{m}-K_{E}\right|}{K_{E}} \times 100
$$

where $\delta_{i}=$ Percentage deviation of single sample data, $\mathrm{K}_{\mathrm{E}}=$ Experimental Thermal conductivity, $\mathrm{K}_{\mathrm{m}}=$ Model (Predicted) Thermal conductivity

$$
\sum\left|K_{m}-K_{E}\right|=0.021 ; \delta=\sum_{i=1}^{n} \delta_{i}=54.166
$$

where $\delta$ is the total percentage deviation of all the samples and $\mathrm{n}$ is the number of sample data $=9$

$$
\bar{\delta}=\frac{\sum_{i=1}^{n} \delta_{i}}{n}=\frac{54.166}{9}=6.02 \%
$$

From the analysis, the accuracy of the model is given in Equation 5.

$$
\begin{aligned}
& \text { Accuracy }=(100-\bar{\delta}) \% \\
& 100-6.02=93.98 \% \cong 94 \% \\
& \therefore \text { The accuracy of the model }=94 \% \\
& \delta=\sum_{i=1}^{n} \delta_{i}=58.08
\end{aligned}
$$

Where $\delta$ is the total percentage deviation of all the samples and $\mathrm{n}$ is the number of sample data $=9$

$$
\bar{\delta}=\frac{\sum_{i=1}^{n} \delta_{i}}{n}=\frac{58.08}{9}=6.45 \%
$$

From the analysis, the accuracy of the model is given as

$$
\text { Accuracy }=(100-\bar{\delta}) \%=93.55 \% \cong 93.6 \%
$$

$\therefore$ The accuracy of the model $=93.6 \%$

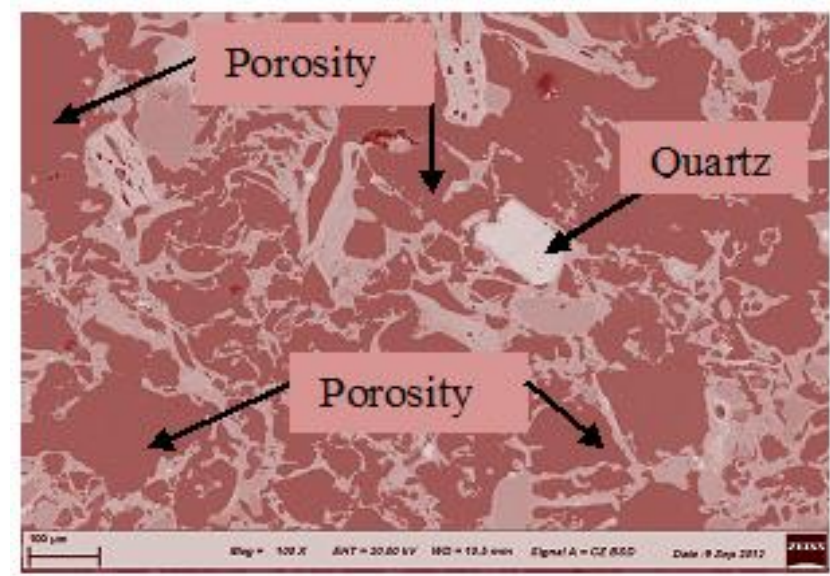

Plate 2: $40 \%$ additive fired at $1150^{\circ} \mathrm{C}$, Scale: 100 $\mu \mathrm{m}$ 


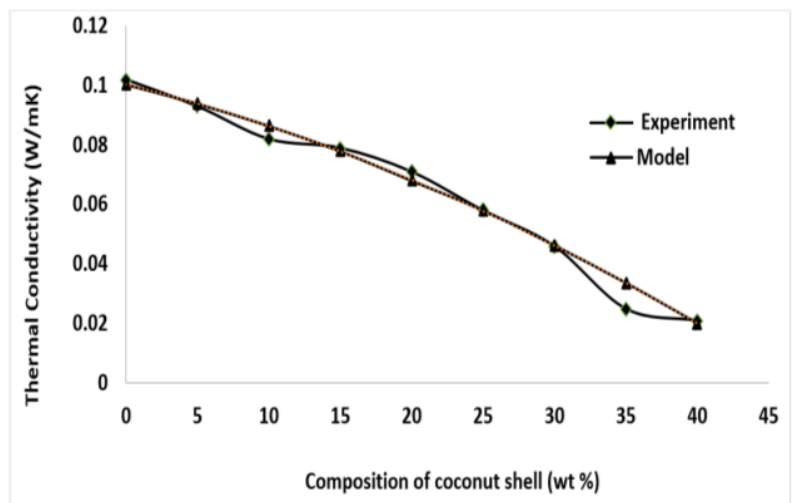

Figure 1 (a): Variation of thermal conductivity of Osiele bricks with \% composition of coconut shell particulate, experimental and model

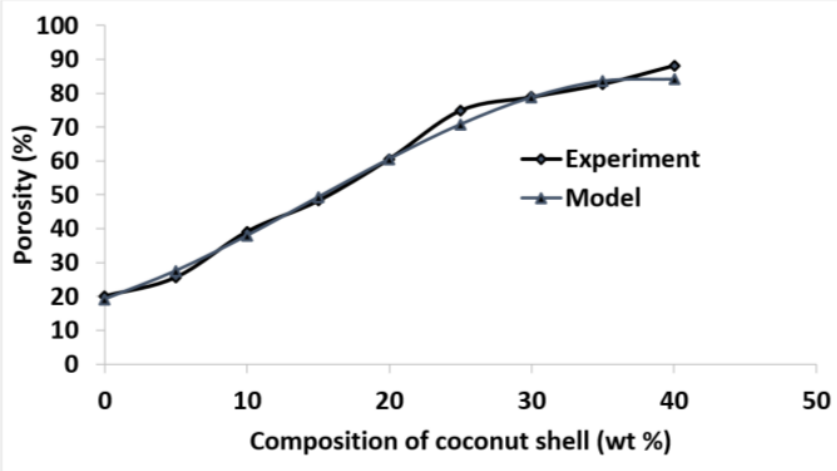

Figure 3: Experimental and model validation showing porosity as a function of the amount of coconut shell particulates

\subsection{Physical Properties}

\subsubsection{Porosity of Bricks from Osiele clay}

The result in Figures 3 and 4 indicates that porosity varies directly with percentage composition of coconut shell particulates. This is as a result of sintering process, during which the coconut shell burnt off thereby creating pores.

$$
\delta=\sum_{i=1}^{n} \delta_{i}=28.3
$$

Where $\delta$ is the total percentage deviation of all the samples and $\mathrm{n}$ is the number of sample data $=9$

$$
\bar{\delta}=\frac{\sum_{i=1}^{n} \delta_{i}}{n}=\frac{28.3}{9}=3.14 \%
$$

From the analysis, the accuracy of the model is given as

Accuracy $=(100-\bar{\delta}) \%=96.86 \% \cong 97 \%$

$\therefore$ The accuracy of the model $=97 \%$

\subsubsection{Porosity of Bricks from Ukpor clay}

$\sum\left|P_{m}-P_{E}\right|=16.32 \quad \delta=\sum_{i=1}^{n} \delta_{i}=28.05$

$\delta=\sum_{i=1}^{n} \delta_{i}=28.05$

Where $\delta$ is the total percentage deviation of all the samples and $\mathrm{n}$ is the number of sample data $=9$

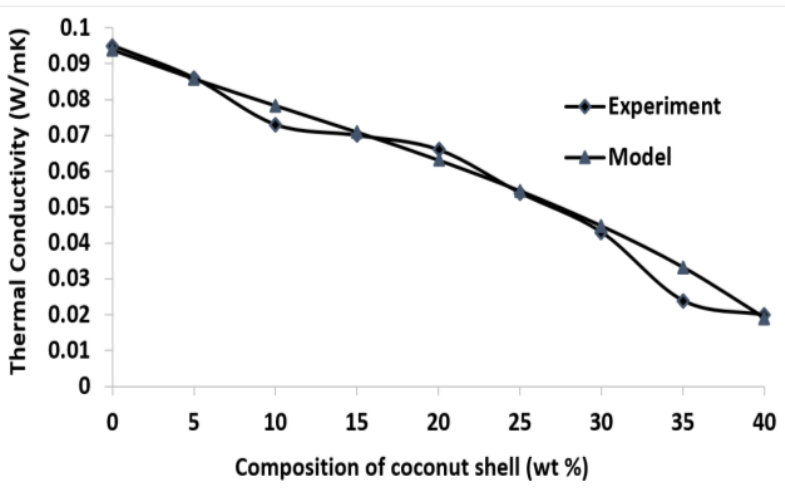

Figure 2: Variation of thermal conductivity with percentage composition of coconut shell experimental and model validation.

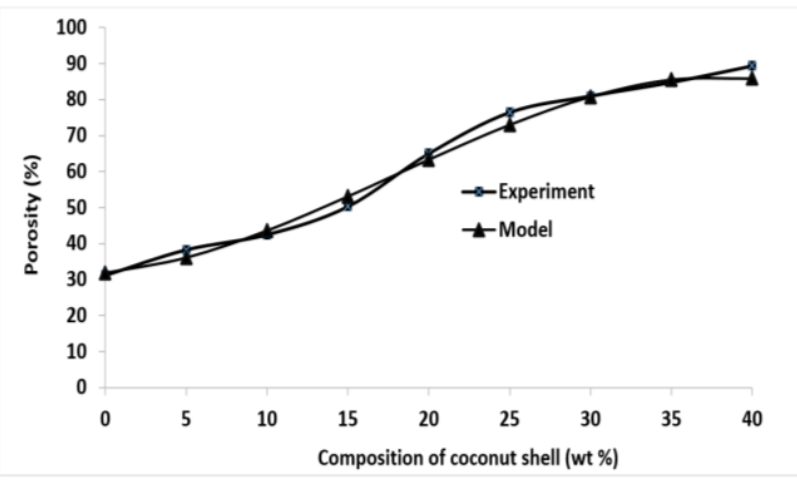

Figure 4: Model and experimental Validation showing variation of porosity with percentage composition of coconut shell particulates.

$$
\bar{\delta}=\frac{\sum_{i=1}^{n} \delta_{i}}{n}=\frac{28.05}{9}=3.12 \%
$$

From the analysis, the accuracy of the model is given as

Accuracy $=(100-\bar{\delta}) \%=96.88 \% \cong 97 \%$

$\therefore$ The accuracy of the model $=97 \%$

\subsection{Mechanical Property}

\subsubsection{Cold Crushing Strength of Bricks from Osiele clay}

The results in Figure 5 and 6 indicate that cold crushing strength decreases with increase in percentage composition of coconut shell. This could be attributed to increase in porosity which resulted from the escape of coconut shell at high temperature which created pores thereby reducing the strength of the bricks.

$$
\begin{gathered}
\sum\left|S_{m}-S_{E}\right|=962 \quad \delta=\sum_{i=1}^{n} \delta_{i}=22.93 \\
\delta=\sum_{i=1}^{n} \delta_{i}=22.93
\end{gathered}
$$

Where $\delta$ is the total percentage deviation of all the samples and $\mathrm{n}$ is the number of sample data

$$
\bar{\delta}=\frac{\sum_{i=1}^{n} \delta_{i}}{n}=\frac{22.93}{9}=2.54 \%
$$

Vol. 38, No. 2, July 2019 


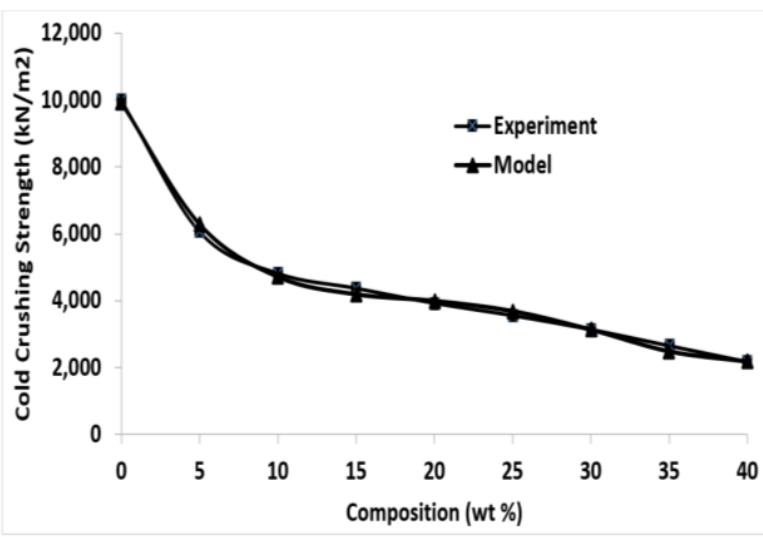

Figure 5: Model and experimental validation showing CCS as a function of percentage composition of coconut shell particulates

From the analysis, the accuracy of the model is given as:

Accuracy $=(100-\bar{\delta}) \%=97.46 \% \cong 97.5 \%$

$\therefore$ The accuracy of the model $=97.5 \%$

\subsubsection{Cold Crushing Strength of Bricks from Ukpor clay}

$$
\sum\left|S_{m}-S_{E}\right|=1130.4 ; \quad \delta=\sum_{i=1}^{n} \delta_{i}=40.15
$$

Where $\delta$ is the total percentage deviation of all the samples and $\mathrm{n}$ is the number of sample data

$$
\bar{\delta}=\frac{\sum_{i=1}^{n} \delta_{i}}{n}=\frac{40.15}{9}=4.46 \%
$$

From the analysis, the accuracy of the model is given as

Accuracy $=(100-\bar{\delta}) \%=95.54 \% \cong 95.5 \%$

$\therefore$ The accuracy of the model $=95.5 \%$

The results indicate that the model predicts the thermal conductivity, cold crushing strength and percentage of porosity obtained at a given weight percentage of coconut shell added. The results obtained from the model generated show close correlation and trend similar to experimental results.

Deviational analysis conducted using mean deviation indicates that the deviation of model-predicted data from the experimental data is between $2.25-8.9 \%$. This translates into over $91-97 \%$ accuracy. Therefore, over $97 \%$ operational confidence level for the derived model is assured.

\section{CONCLUSION}

The addition of agroforestry wastes to the selected Nigerian fireclays with appropriate mix formulation and thermal regime creates pores that are evenly

Nigerian Journal of Technology,

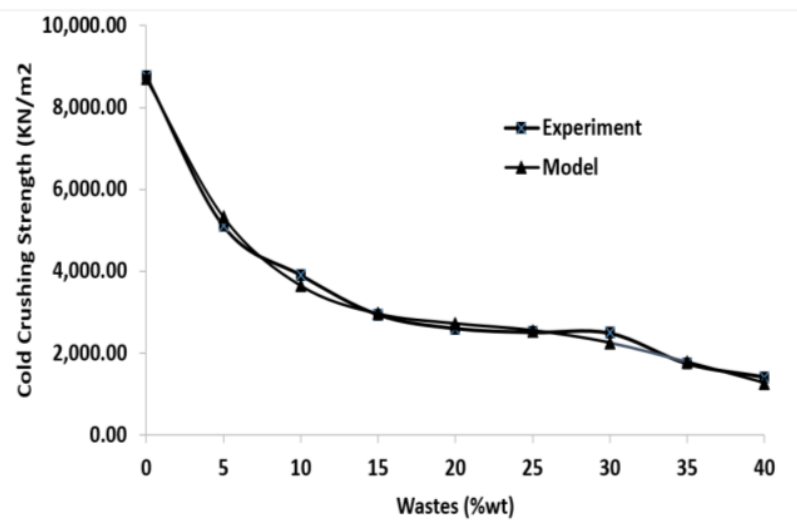

Figure 6: Experiment and model Validation showing CCS as a function of percentage composition of coconut shell particulates.

distributed in the structure of the bricks. This accounts for the improvement in the insulating property as well as the mechanical property (strength) of the developed bricks.

The developed empirical models have high level of accuracy (91-97\%). The results of simulation using finite element method show strong correlation with the experimental findings.

\section{REFERENCES}

[1] Bhatia, A. Overview of Refractory Materials. Retrieved from www.PHDonline.org accessed online Feb. 2012 pp. 10-54.

[2] Esezobor D. E., Obidiegwu E. O., and Lawal G. I. The Influence of Agro-forestry waste additive on Thermal Insulating Properties of refractory bricks from Osiele Clay. Journal of Emerging Trends in Engineering and Applied Sciences Vol. 5 Number 5, 2014, pp. 305-311.

[3] Olasupo, O. A., and Borode, J. O. Development of Insulating Refractory Ramming Mass from Some Nigerian Refractory Raw Materials. Journal of Minerals \& Materials Characterization\& Engineering, vol. 8 Number 9, 2009, 667-678.

[4] Hassan, S. B., and Aigbodion V. S. Effect of Coal ash on some refractory properties of aluminasilicate (Kankara) clay for Furnace Lining. Egyptian Journal of Basic and applied Science Vol.1, Number 2, 2014, pp.107-114.

[5] Jonker, A. (2006). Insulating Refractory Materials from inorganic Wastes Resources, PhD thesis submitted to the Department of Chemistry, Tshwane University of Tech, Pretoria, 2006, pp.11-47.

[6] Ali, L., Anwar, M., Rafiq, M., Haq, E. u., \& Shahzad, K. Manufacturing Of Light-Weight Refractory 
Bricks Using Local Raw Materials. Journal of Faculty of Engineering \& Technology, Pakistan, 2017, pp. 31-41.

[7] Ahmad, S., Iqbal, Y., \& Muhammad, R. (2017). Effects of coal and wheat husk additives on the physical, thermal and mechanical properties of clay bricks. Boletin De La Sociedad De Ceramica Y Vidrio. 2017, Pp. 131-138.

[8] ASTM C133-97. American Standard Testing and materials test Methods for Cold crushing Strength and Modulus of Rupture of refractories, ASTM
International, West Conshohocken, P.A. 2008. DOI10.1520/C0133-97R08.

[9] ASTM C20-00. American Standard Testing Methods and Materials Test Method for Porosity and Bulk Density. ASTM International, West Conshohocken, P.A. 2010. DOI: 10.1520/C0020.

[10]Nwoye C. I, Obidiegwu E. O and Nwankwo N. E, Model for Computational Analysis and Predictive Assessment of Bulk Density of fired bricks based on incurred Shrinkage, Journal of Innovative Research in Engineering and Science Vol. 2, Number 1, 2011 pp. 74-82. 